\title{
LA ESCUELA DE PAPEL. AgENCIAS Y AGENTES EDUCATIVOS EN ATACAMA. MUNICIPIO DE CALAMA Y COMUNIDADES ATACAMEÑAS (1888-1950)
}

\author{
Carlos Mondaca ${ }^{1}$ y Alberto Díaz ${ }^{2}$
}

\section{* Introducción}

Resumen

Se analiza el proceso de incorporación de los territorios del desierto de Atacama al Estado chileno, discutiendo la implementación del sistema educacional en el Departamento de El Loa durante las primeras mitad del s. XX. Se propone desde la documentación histórica que tanto el municipio de Calama, los agentes locales y la población atacameña articularon la institución escolar chilena, activando una serie de proyectos e iniciativas educativas locales como la edificación de recintos escolares sin el apoyo gubernamental, contradiciendo los discursos de eficiencia que argumentaba el Estado desde la metrópolis.

Palabras claves: Calama - escuela chilena - comunidades - Atacama.

Abstract

We analyze the process of incorporation of the territories of the Atacama Desert in Chile, by considering the implementation of the educational system in the Departamento de El Loa during the first half of Twenty Century. Based on historical documentation we propose that was the Municipality of Calama, local agents and the atacamenians who articulated the Chilean school at regional level, becoming relevant actors, which contradicts the discourse of efficiency and effectiveness of the State from the metropolis.

Key words: Calama - Chilean school - communities - Atacama. Recibido: abril 2013. Aceptado: agosto 2013.

1 Universidad de Tarapacá, Departamento de Educación y Humanidades. Av. 18 de Septiembre 2222, Arica, CHILE. Email: cemondacar@uta.cl

2 Universidad de Tarapacá, Departamento de Ciencias Históricas y Geográficas. Av. 18 de Septiembre 2222, Arica, CHILE. Email: albertodiaz@uta.cl
Iniciada la Guerra del Pacífico en 1879, desde Santiago se requirió la administración del Departamento de El Loa, con el propósito de incorporar a la población de Atacama a los patrones políticos, culturales e identitarios de la nacionalidad chilena. Esta tesis, propiciada desde el Estado excluyente, necesitó de la agencia sociopolítica de la administración municipal para la organización del territorio, regulando las actividades productivas (González 2008) y la integración del conjunto de la población a los valores patrios (Góngora 2006 [1986]; Fernández 2003; Aguirre y Mondaca 2011). ${ }^{3}$

Al respecto, las articulaciones entre las agencias gubernamentales y la comunidad propiciaron la implementación de un proceso de modernización y la articulación de una activa ciudadanía (Ochman 2006), permitiendo el desarrollo de la administración con un poder estructural (Wolf 2001 [1956]), siendo representadas en las escuelas, servicio de correos, telégrafos, construcción de obras públicas, servicio militar obligatorio, regulación en temas de higiene y salubridad pública, instalación de mercados y mataderos, reglamentación de las aguas y cárceles, entre otros. ${ }^{4}$

La institucionalidad pública regional promovió iniciativas con ciertos matices locales, buscando cristalizar los planes y proyectos generados entre los segmentos políticos metropolitanos (Sanhueza y Gundermann 2007; Mondaca y Ogalde 2012). Estos procesos históricos focalizados, y a escala reducida, permiten problematizar que 
los procesos de incorporación al Estado corresponden también, a una dinámica de articulación entre las instituciones y los pobladores. Fue este último grupo el que impulsó y accionó los mecanismos modernizantes como resultado de los usos políticos de la ciudadanía regional en Atacama. Para los fines de este estudio, la consolidación de la escuela responde a un mecanismo modulado por una ciudadanía activa (Marshall 1992 [1950]), donde la participación de los comuneros en la política local se vincula con las agencias gubernamentales, generando en la praxis política cotidiana, redes entre el Estado y la comunidad por medio del municipio, "actuando como puentes entre diferentes niveles de decisión” Wolf (2001 [1956]: 1075). ${ }^{5}$

Sobre la base de estos supuestos, examinamos cómo muchos de los proyectos educativos propiciados en teoría por el Estado y las autoridades desde la metrópolis, no lograron materializarse en las aldeas cordilleranas y en los oasis de la actual región de Antofagasta, quedando dichas

3 Ambos aspectos fueron necesarios debido a la apertura de mercados y capitales extranjeros que promovieron el crecimiento demográfico y la expansión industrial y minera en esta zona (Sanhueza y Gundermann 2009). En este sentido, el Estado operó como "uno nacionalista" (sensu Parekh 2000: 103), y no como uno nacional, pues no debió solo intentar implantar el nacionalismo chileno; sino que, además, debió enfrentar un proceso de integración de la población boliviana e indígena atacameña presente en la zona; la que de acuerdo a Sanhueza y Gundermann (2007, 2009), rápidamente se integró a las dinámicas de la nueva administración nacional. Ambos grupos como comunidad local actuaron como agentes de cohesión social y ejercieron una fuerza centrípeta en sus prácticas sociopolíticas de forma autónoma en la administración de los oasis de Calama y valles cordilleranos, en relación a la metrópoli.

4 La expresión máxima de esta participación y autonomía la encontramos en la Corporación Municipal de Calama, la cual desde sus inicios se transformó en una institución sistematizadora no solo de las necesidades y demandas de la población, sino que también de la coordinación de todos los servicios públicos de las ciudades y pueblos bajo su jurisdicción mediante la organización de asambleas, comisiones y juntas vecinales, y la realización de mejoras a partir de la acción de las comunidades de acuerdo a sus propias necesidades (Sánchez 2010; Mondaca y Ogalde 2012). Lo que por cierto, era inherente al discurso civilizador de progreso vs. barbarie del Estado chileno.

5 Este autor define a esta particularidad como brokers, que corresponden a los grupos que median entre los grupos intracomunitarios y los grupos organizados de nivel nacional que operan primariamente dentro de las instituciones (Catullo 2006). intenciones solo en el papel, ya que la concreción efectiva de dichos proyectos educacionales fueron asumidos por la población local en concomitancia con el municipio de Calama. Así, el rol de las agencias y agentes locales fue gravitante al sostener una serie de acciones que resolvieron problemas y demandas educativas de los habitantes de Atacama, reproduciendo a su vez, los valores nacionales y modernos en la escuela. Esta institución, amén de una serie de acciones complejas para constituirse en la zona, permitió fraguar los requerimientos de los ciudadanos, comuneros y sus autoridades, forjando durante las primeras décadas del s. XX, una sociedad regional que se debatió entre el Estado centralista, la minería, la modernización y la adscripción ciudadana, constituyéndose en la base de la construcción de la nación chilena en los territorios otrora atacameños y bolivianos.

\section{* El municipio y la escuela chilena EN EL LOA (1888-1930)}

El 13 de julio de 1888 fue promulgado por el presidente Balmaceda el Decreto de Ley 3346 para la creación de la provincia de Antofagasta, organizándose de esta forma la Corporación Municipal de Calama (aunque nominalmente se había creado el 23 de marzo de 1879), constituyéndose el 13 de octubre de 1888 con la sesión de la primera Junta de Alcaldes de Calama. ${ }^{6}$ El 22 de diciembre de 1891 se organizó el territorio comunal integrando a las subdelegaciones rurales de Sierra Gorda, Caracoles, San Pedro de Atacama y Ascotán.7 Desde entonces, esta institución se transformó en la administradora, no solo de las necesidades y demandas de la población, sino también de la coordinación de todos los servicios públicos de las ciudades y poblados bajo su jurisdicción, mediante la organización de asambleas, comisiones y

\footnotetext{
6 Archivo de la Corporación Municipal de Calama (de ahora en adelante ACMC), Libro 1. Actas de Instalación de Sesiones de la Municipalidad de Calama, fojas 1, 2. El Municipio de Calama se componía de tres alcaldes, nueve regidores, un secretario - de los cuales solo los dos primeros eran elegidos directamente a través del sufragio universal-, y delegados (designados) de los distintos distritos circunscritos a su jurisdicción, los electores eran los mayores contribuyentes.

7 Archivo Nacional. Fondo Intendencia de Antofagasta (en adelante ANFIA). Ministerio del Interior, $n^{\circ}$ 2297, Santiago, 22 de diciembre de 1891.
} 


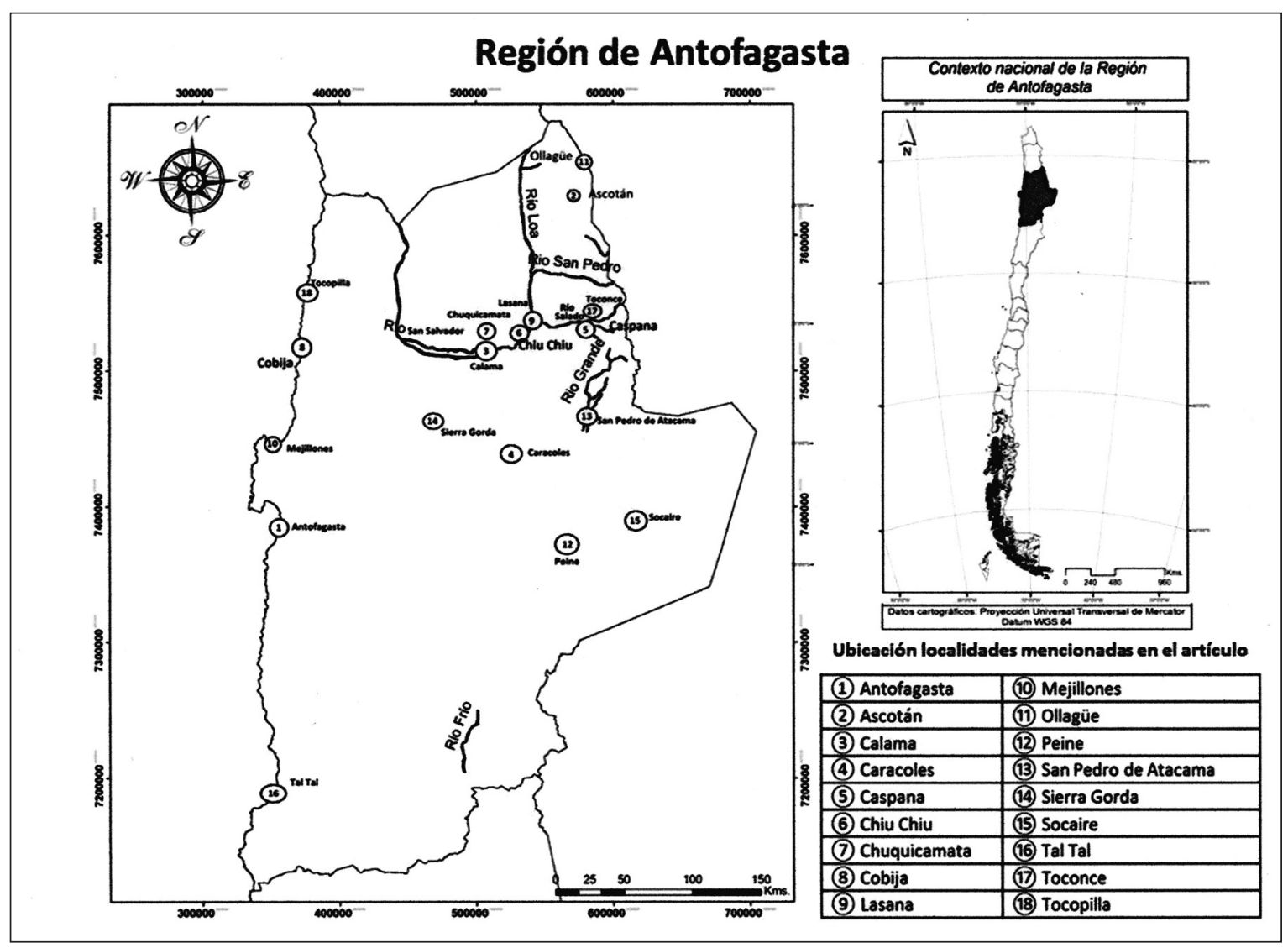

Figura 1. Mapa de la región de Antofagasta, en el norte de Chile, que muestra los principales lugares mencionados en el texto.

juntas vecinales, y la realización de mejoras a partir de la acción de la población de acuerdo con sus propias necesidades. ${ }^{8}$

Aunque en principio eran los subdelegados los representantes directos del poder central, quienes debían presidir la municipalidad y sus sesiones, promulgar y ejecutar las

8 Al respecto, Sanhueza y Gundermann señalan que una vez establecidas las autoridades civiles, se creó la Intendencia y provincia de Antofagasta, la cual fue subdividida en los departamentos de Taltal, Tocopilla y Antofagasta, y éstos a su vez en municipios y subdelegaciones. El Departamento de Antofagasta estaba compuesto por las municipalidades costeras de Mejillones y Antofagasta, y Caracoles y Calama en los territorios interiores, agrupando en ellas un total de nueve subdelegaciones, "cuatro de ellas correspondientes a esa ciudad, a Mejillones y a los establecimientos salitreros; en tanto las del interior eran Sierra Gorda, Caracoles, Calama, Ascotán y San Pedro de Atacama" (2007: 122). ordenanzas, intervenir en la elaboración de los presupuestos, declarar la nulidad de los acuerdos corporativos y administrar los bienes y rentas, en la práctica fue la alcaldía municipal la que asumió dichas responsabilidades burocráticas según la impronta sociopolítica del Estado-nación chileno. Era necesario ejercer soberanía en los nuevos territorios anexados, utilizando todos los instrumentos disciplinadores que el Estado moderno poseía, como la custodia del orden público, el reclutamiento militar y/o la escuela, siendo esta última la que nos interesa analizar.

En el plano educativo, el municipio de Calama puede ser comprendido teóricamente como un aparato reproductor de la nación que buscó disciplinar y asimilar a la población de Atacama a una condición de chilenidad. Si es así, entonces la construcción (y reproducción) de los símbolos de la nación desde la escuela, se imbricarían con la 
inserción de políticas que representarían el quehacer administrativo del Estado chileno en la región. A la inversa, la demanda por la educación posee lecturas y significados propios para las comunidades, quienes requerían acceder a ella para integrarse a la modernidad que pregonaban las agencias políticas. De esta manera, las autoridades gubernamentales impulsaron incipientemente un sistema de escuelas en las ciudades costeras, cantones salitreros y en los oasis atacameños, proyectos que ya antes el Estado colonial y Bolivia habían instituido. ${ }^{9}$ Veamos ahora algunos casos que grafican las acciones del municipio y el rol de las comunidades atacameñas.

A inicios de 1880 existían solo dos escuelas primarias funcionando en Antofagasta. ${ }^{10}$ Para junio de aquel año se autorizó la creación de una "Escuela de Hombres" para Calama, ${ }^{11}$ regentada por el preceptor Honorio Rojas, y para agosto se organizó la "Escuela para Mujeres" dirigida por Gregorio Vicuña, ${ }^{12}$ dotándolas de recursos

9 La escuela no fue algo ajeno al espacio atacameño. Desde 1776 hay antecedentes históricos sobre la presencia de escolarización en la escuela de Toconao, a cargo de la Iglesia, también en Chiu Chiu y en San Pedro de Atacama (Hidalgo 1984). Para la época republicana y bajo el dominio boliviano, Cajías (1975), señala la mantención de una escuela primaria en el puerto de Cobija. Al respecto, el Estado boliviano realiza esfuerzos de soberanía en el litoral, procura la creación de escuelas, no solo en Cobija sino en otros pueblos cabecera de Calama, donde los gobernantes de entonces, procuran exitosas gestiones esperando el progreso atacameño. Según el Catálogo n 249 del Archivo Nacional, vol. 1888 de 1842 a 1933 de creación de escuelas que según el Decreto de Ley 1733 del $1^{\circ}$ de junio de 1885 , se crean en esa fecha la escuela mixta s/n| en Calama (vol. 541), escuela mixta s/n en San Pedro de Atacama (vol. 557) y escuela mixta en Chiu Chiu (vol. 557). Según vol. 1976 (30 de junio de 1988) se trasladó la escuela mixta $n^{\circ} 3$ de Chiu Chiu a Sierra Gorda (vol. 698) y otras escuelas con denominación $2^{\circ}$ en Calama, $3^{\circ}$ en Calama (vol. 598), y que según vol. 911 (29 de marzo de 1890) se crean las escuela de niñas $n^{\circ} 6$ $y^{\circ} 7$ en Calama y en San Pedro de Atacama (vol. 731).

${ }^{10}$ ANFIA, vol. 2. Ministerio de Justicia (1879-1883). N 1128. Santiago, 15 de mayo de 1880 .

${ }^{11}$ ANFIA, vol. 2. Ministerio de Justicia (1879-1883). N 1128. Santiago, 4 de junio de 1880 .

${ }^{12}$ ANFIA, vol. 2. Ministerio de Justicia (1879-1883). N 1133. Santiago, 18 de agosto de 1880. En el Folio 1515 desde Santiago, el 9 de septiembre de 1880 , se informa de la creación de escuela mixta en el Puerto de Tocopilla, pedida en junio por la junta municipal de Tocopilla. En el Folio 1098 desde Santiago, el 30 de mayo de 1881 se informa del envío de un presupuesto por la instalación y sostenimiento de dos escuelas en el distrito de Caracoles, infor- bibliográficos para su funcionamiento. ${ }^{13}$ Como aun Chile estaba en guerra con Perú y Bolivia, se requería saber cuántas escuelas para hombres y mujeres existían en toda la zona, qué tipo de gastos económicos poseían y si los preceptores eran idóneos para ejercer la docencia. ${ }^{14}$ Existía cierta preocupación por el poco o casi nulo presupuesto que poseían las escuelas y la forma en que solventaban sus gastos durante los tiempos de guerra..$^{15}$

En noviembre de 1882, el comandante a cargo de la implementación de la estructura administrativa chilena, consultó a las autoridades de Santiago acerca de cómo podían ser integrados al presupuesto de la Gobernación de Antofagasta los gastos que generaba "la escuela que actualmente funciona en San Pedro de Atacama". ${ }^{16}$ Desde el gobierno central respondieron que:

\section{“[...] este ministerio hará indicación en el Congreso, al discutirse el proyecto de lei de presupuesto para el año estrante para que se invierta en cuatro mil pesos el interés destinado al ausilio de la instrucción, primaria en este territorio, a fin de dotar dos escuelas en San Pedro de Atacama". ${ }^{17}$}

A un año de la indicación, fue el mismo Ministerio de Justicia el que informó que asumiría los costos "por el sueldo que correspondía a la preceptora de San Pedro de Atacama desde diciembre de 1882 hasta junio inclusive del presente año i por la condición de una pizarra para la escuela mencionada. ${ }^{18}$ Para 1888 el municipio de Ca-

mación que se complementa con el Folio 1221 desde Santiago el día 17 de junio de 1881, donde se autorizá la instalación de las escuelas en Caracoles, una para hombres y otra para mujeres.

13 ANFIA, vol. 2. Ministerio de Justicia (1879-1883). $\mathrm{N}^{\circ} 1627$. Santiago, 13 de octubre de 1880 .

${ }^{14}$ ANFIA, vol. 2. Ministerio de Justicia (1879-1883). N 1026. Santiago, 17 de octubre de 1881.

15 ANFIA, vol. 2. Ministerio de Justicia (1879-1883). $\mathrm{N}^{\circ} 1445$. Santiago, 26 de septiembre de 1882

${ }^{16}$ ANFIA, vol. 2. Ministerio de Justicia (1879-1883). $\mathrm{N}^{\circ} 2568$. Santiago, 06 de noviembre de 1882.

${ }^{17}$ ANFIA, vol. 2. Ministerio de Justicia (1879-1883). $\mathrm{N}^{\circ} 2741$. Santiago, 30 de noviembre de 1883 .

${ }^{18}$ ANFIA, vol. 2. Ministerio de Justicia (1879-1883). N²871. Santiago, 21 de diciembre de 1883 . Cabe señalar que el $1^{\circ}$ de junio de 1885 , se crea la escuela pública fiscal de San Pedro de Atacama. Según el Censo Nacional realizado el 26 de noviembre de 1885, asistían a la escuela un varón y tres niñas. Existían establecimientos educacionales en Calama, con 12 niños y 18 niñas, 
lama asumió íntegramente la implementación de las escuelas en los oasis y poblados adyacentes. A un mes del inicio de las funciones municipales, el 27 de noviembre se aprobó el "Presupuesto de ingresos y egresos de la municipalidad de Calama para el año 1889. EGRESOS. PARTIDA $4^{\circ}$ - INSTRUCCIÓN. ITEM UNICO: PREMIO A LOS ALUMNOS DE LAS ESCUELAS 50 pesos", que integrará en un año recursos de instrucción con $\$ 760$, y el mismo ítem para los premios para alumnos por celebrar las fiestas patrias. ${ }^{19}$ En 1889 , el monto ascendió a $\$ 1070$. Para 1891 se presentó el proyecto para la escuela municipal de niñas, contemplando gastos de instalación, sueldo de la preceptora, el arriendo del local e incluso un gasto menor destinado para invertir en premios para los estudiantes. Sin embargo, el subdelegado objetó el proyecto, al señalar que al instalar una escuela municipal de estas características, el colegio perteneciente al Gobierno podría ver mermada la asistencia de alumnas, debido a que los vecinos prefirieran hipotéticamente la escuela municipal, peligrando incluso su existencia. ${ }^{20}$ Duran-

en Chiu Chiu, con 12 varones, y en Ascotán, con 19 niños y 16 niñas. La población de las $6^{a}$ y $7^{a}$ subdelegaciones del territorio de Antofagasta, que comprendía la región atacameña, incluyendo las actuales comunas de Ollagüe, Calama y San Pedro de Atacama, era de 3983 personas. El 23.6\% de las cuales sabía leer, el 21.56\% sabía escribir y el 20.3\% asistía a la escuela (INE 1889). Del censo realizado el 28 de noviembre de 1895 (INE 1900), existían cinco establecimientos de educación primaria en la $6^{\mathrm{a}} \mathrm{y} 7^{\mathrm{a}}$ subdelegaciones de la provincia de Antofagasta. En la 6 a subdelegación, distrito 1 (Calama), había una matrícula de 34 alumnos; en el distrito 2, de cuatro alumnos; $y$, en el distrito 4 (Ascotán), de 20 alumnos; el distrito 3 aparece sin matrícula escolar. En la $7^{\text {a }}$ subdelegación funcionaban dos escuelas, una en el primer distrito (San Pedro de Atacama), con 62 alumnos y otra en el $2^{\circ}$ distrito (Toconao) con cuatro alumnos. La población de ambas subdelegaciones llegaba a 2924 personas, 1118 sabían leer (40.49\%), 1117 sabían escribir (38.2\%) y 124 asistían a la escuela (4.24\%). En 1907, la $7^{\mathrm{a}}$ subdelegación de Calama, la $8^{\mathrm{a}}$ de Ascotán y la $9^{\mathrm{a}}$ de San Pedro de Atacama, con una población de 9525 personas, de las cuales 3967 sabían leer (41.64\%) (INE 1910). El censo de 1920 (INE 1929), menciona una población de 19.403 de las cuales sabían leer un $58.28 \%$. Para las tres subdelegaciones la población escolar de seis a 14 años, era de 3772 niños de los cuales 1611 sabían leer. En 1930, el Departamento de El Loa tenía una población de 24.257 habitantes y una población escolar de 4298 estudiantes y un 20.9\% de analfabetos (Gómez 1995).

${ }^{19}$ ACMC, Libro 1 (1894-1897), $11^{a}$ sesión y 6 o ordinaria del 27 de noviembre de 1888. Fojas 23, 24 25, 26, 27. El premio era para las fiestas patrias.

${ }^{20}$ ACMC. Libro 1 (1888-1894) 10 $0^{a}$ sesión y $3^{a}$ extraordinaria celebra- te el debate, el alcalde replicó declarando que, "aunque en diversas ocasiones las autoridades i vecinos de la localidad han formulado se hagan quejas, el mal subsiste hasta hoy". Finalmente, el proyecto se llevó a votación, aprobándose los recursos para la creación de esta escuela municipal. ${ }^{21}$ Este suceso, que no es aislado, describe el ánimo que envolvía a las autoridades, como asimismo, manifiesta una preocupación que deja entrever el potencial impacto de la educación municipal en oposición a la instrucción estatal, la que poseía evidentes problemas en su implementación. Al respecto, el municipio de Calama asumirá un rol protagónico para el establecimiento de las escuelas, respondiendo al unísono a los requerimientos ministeriales y principalmente de la población de Atacama, la cual tenía sus propias iniciativas que buscaban el reconocimiento y apoyo estatal.

En julio de 1896, el municipio aprobó la solicitud de los comuneros de Chiu Chiu para crear una escuela mixta para niños en aquél distrito, ${ }^{22}$ aunque solo para el 17 de mayo de 1902 se discutió la entrega de una subvención municipal para pagar la remuneración de la preceptora, la cual argumentaba que "la municipalidad esta llamada para fomentar todo aquello que tienda a la instrucción, y bien estar del pueblo".23

En el caso de Calama, en 1898 se discutió "una solicitud del Señor Cancino Ancón Magdalen pidiendo el correspondiente permiso para establecer en este pueblo una escuela particular para niños", la que fue aprobada por unanimidad. ${ }^{24}$ Iniciado el s. XX, se autoriza al intendente de Antofagasta:

"[...] para reducir a escritura publica el contrato que ha convenido celebrar con don Daniel Cerda Carrasco en virtud del cual

da el 27 de diciembre de 189o. Fojas 61, 62, 63, 64, 65, 66, 67.

${ }^{21}$ ACMC, Libro 1 (1888-1894). $10^{\text {a }}$ sesión y $3^{a}$ extraordinaria celebrada el 27 de diciembre de 1890 . Fojas 61, 62, 63, 64, 65, 66, 67.

${ }^{22}$ ACMC, Libro 2 (1894-1897. Sesión ordinaria celebrada el 16 de Julio de 1896.

${ }^{23}$ Archivo Nacional. Fondo Municipalidad de Calama (en adelante ANFMC). Vol. 3. Libro de sesiones de la Ilustre Municipalidad de Calama. Iniciado el 15 de febrero de 1897 con el folio 1 y terminado el 14 de febrero de 1903 . Folio s/n; 17 de mayo de 1902.

${ }^{24}$ ANFMC, vol. 1, n ${ }^{\circ} 3$. Libro de sesiones de la Ilustre Municipalidad de Calama. Iniciado el 15 de febrero de 1897 con el folio 1 y terminado el 14 de febrero de 1903. Folio 152; 14 de agosto de 1898. 
este ultimo da un [i?] al fisco la casa de su propiedad situada en Calama para que funcione en ella una escuela pública". ${ }^{25}$

En 1900 se elaboró el "Informe de la Comisión nombrada por la H. Corporación, sobre la instalación de una escuela para niños", estableciendo la cantidad de $\$ 80$ para arrendar el local de la escuela de Calama, dándose visto bueno de ejecución. ${ }^{26}$ Para junio de aquel año se responde a Andrés Ojeda sobre la solicitud para comprar lo que necesita la escuela de forma más urgente; desde el municipio se responde que "se estima más conveniente se le asigne un sueldo al Señor Ojeda, en vez de los ochenta pesos", solicitud que fue aprobada por consenso. ${ }^{27}$

En este entramado de cierta efervescencia educativa, el municipio adquiere protagonismo, tanto como receptor de las demandas de los agentes locales, y como promotora de las mismas, movilizando diversos recursos para los proyectos educativos, dada la compleja situación de las escuelas fiscales. Por ejemplo, para 1913 desde la localidad de Peine se informó:

"Habiendo tomado datos respecto de la población escolar que haya en Peine he obtenido los siguientes:

Que hai un número de 35 á 40 niños que puedan asistir a la escuela i que es verdad que entre todos los vecinos de ésa han construido un edificio bastante cómodo para la escuela.

La distancia de este pueblo á Peine es de 25 leguas más o menos. Dios Guarde a US.

\section{Rojas}

Subdelegado de San Pedro de Atacama. Al señor Intendente Antofagasta". ${ }^{28}$

Asimismo, hay casos similares para la periferia de Chuquicamata. El 30 de marzo de 1915 se expone la posible fundación de una escuela en Punta de Rieles, dado el gran número de niños "que allí crecen sin tener los beneficios de la enseñanza primaria le obligan a solicitar de la

\footnotetext{
${ }^{25}$ ANFIA. Ministerios de Justicia e Instrucción Pública. 19001905. Vol. 4, n 96), 24 de enero de 1900.

${ }^{26}$ ANFMC, vol. 1. Libro 3 de sesiones de la Ilustre Municipalidad de Calama. Iniciado el 15 de febrero de 1897 con el folio 1 y terminado el 14 de febrero de 1903. Folio s/n; 20 de junio de 1900.

${ }^{27}$ ANFMC, vol. 1. Libro 3 de sesiones de la Ilustre Municipalidad de Calama. Iniciado el 15 de febrero de 1897 con el folio 1 y terminado el 14 de febrero de 1903 . Folio s/n; 30 de junio de 1900.

${ }^{28}$ ANFIA, vol. 11. San Pedro de Atacama 24 de marzo de 1913.
}

Ilustre Corporación la creación de una escuela Mixta para aquel pueblo, cuya importancia y servicios que prestan son indiscutibles". En el municipio se aceptó la idea de crear dicha escuela, disponiéndose la búsqueda de un local, además de fijar el sueldo con cargo a sección "imprevistos" del presupuesto municipal, entre otras acciones. ${ }^{29}$

Debido al repunte de los proyectos educativos municipales, los vecinos de Chiu Chiu:

“[...] piden una subvención municipal para el preceptor de la Escuela que funciona alli, don Felix María Maldonado, quien está por cerrar la Escuela en vista del escaso sueldo que se proporciona entre los vecinos y por la marcada falta de recursos de aquel distrito".

El regidor municipal justificó la petición de los vecinos, pero arguye que:

“[...] primero convendría saber si el Sr. Maldonado tiene alguna preparación para educar. Esto es un asunto bastante delicado; no es posible que estemos subvencionando a personas que no tienen título. El profesor de Placilla por ejemplo no es normalista". ${ }^{30}$

El 20 de noviembre de 1916, se evaluó formar una "Junta de Vigilancia de Instrucción Pública”, siendo integrada por extranjeros, quienes debían revisar las competencias de los docentes. Al respecto, se discutió, que:

"[...] el que conoce esas partes, debe saber lo difícil que es la vida por alli $[. .$.$] y se sabe que desde muy lejos vienen niños a la escue-$ la... [.... Lo único que sé es que hay una existencia de 25 a 30 alumnos [...]. El Rejidor Sr. Benitez [expuso]: El solo hecho de que los vecinos hayan hecho levantar alli una casa para escuela, revela el interés que existe entre ellos por ilustrarse- es cierto que el cura hizo una campaña tenaz contra el actual profesor, por asuntos tal vez de conveniencia clerical; pero puede buscarse otro que no encuentre resistencias partidistas [más adelante agrega:] 'yo tengo en una de las Escuelas una o dos bancas de mi propiedad, las que no pretendo retirar, pero desearía que esos establecimientos fueran dotados de material propio'". ${ }^{11}$

\footnotetext{
${ }^{29}$ ANFMC, vol. 2, n 4 . Libro Actas de Sesiones de la Municipalidad de Calama, Folio 75, 30 de marzo de 1915.

${ }^{30}$ ANFMC, vol. 2, n ${ }^{\circ}$ 4. Libro Actas de Sesiones de la Municipalidad de Calama, Foja 246, 13 de julio de 1916.

${ }^{31}$ ANFMC, vol. 2, n 4 . Libro Actas de Sesiones de la Municipalidad de Calama. Fojas 290, 307, 311 y 317; 20 de noviembre de 1916.
} 
El caso de Chiu Chiu sintetiza el funcionamiento de gran parte de las escuelas creadas durante este período en Atacama. Primeramente, los salarios de los preceptores provenían del aporte de la comunidad, la cual se preocupaba de la manutención de los docentes. En segundo lugar, son los vecinos los que construyen los recintos para que funcionen las escuelas, incluso, la participación de la comunidad en estos proyectos queda evidenciada en el inmobiliario cedido por el mismo regidor: "yo tengo en una de las Escuelas una o dos bancas de mi propiedad, las que no pretendo retirar"; sin embargo, se requerían recursos que materializaran lo anhelado: educarse es sinónimo de modernizarse. ${ }^{32}$ El 21 de diciembre de 1916, se decretan las fecha de exámenes y se nombran las "Comisiones Examinadoras para las escuelas municipales de la Comuna",33 complementándose con la aprobación del "Reglamento y Plan de Estudio de Escuela Profesional de niños Municipal de Calama".34

El aporte local y privado no deja de ser la excepción, como informa un documento fechado el 6 de junio de 1918 de la "Escuela Elemental de Hombres. Municipal de Placilla", detallando que:

"El Señor Primer Alcalde.- Pongo en conocimiento de la Sala que la Chilex ha cedido en la Mina Corina, un local acondicionado debidamente para que funcione la Escuela Elemental de Hombres de Placilla. La Gerencia de la Chilex ha hecho ver a la Alcaldía que es necesario que la Escuela Elemental de Hombres Municipal de Placilla, sea convertida en Escuela Mixta. Hay en Placilla un gran número de niñitas que necesitan instrucción. La Alcaldía interpretando los buenos propósitos que los señores municipales, tienen en bien de la instrucción de la mujer, se ha anticipado a gestionar con la Chilex su ayuda para la atención de una Escuela Mixta...".35

Además, se proponía la construcción "de una Escuela Nocturna para hombres" en Calama, asignándose al preceptor $\$ 200$ que saldrían del pago del agua del ferroca-

\footnotetext{
${ }^{32}$ Los testimonios coinciden con la revisión de los archivos y con esta afirmación. Más antecedentes testimoniales de comuneros atacameños en Mondaca y colaboradores (2008).

33 ANFMC, vol. 2, n 4. Libro Actas de Sesiones de la Municipalidad de Calama. Fojas 347, 351 y 352; 21 de diciembre de 1916.

${ }^{34}$ ANFMC, vol. 2, n ${ }^{\circ}$. Libro Actas de Sesiones de la Municipalidad de Calama. Fojas 32, 33, 38, 39, 43 y 49; 21 de abril de 1917.

35 ANFMC, vol. 2, n 4 Libro Actas de Sesiones de la Municipalidad de Calama. Fojas 229, 230, 243, 235, 237, 243, 247 y 250; 6 de junio de 1918
}

rril.$^{36} \mathrm{El} 24$ de octubre de 1918 se discutió y acordó en el municipio la instalación de la escuela nocturna en Punta de Rieles, siempre y cuando sea ad honorem..$^{37}$ En Ollagüe, uno de los puntos cordilleranos más distantes del territorio, el 23 de junio de 1919 se decretó que se traslade allí "la escuela Mixta Municipal de Placilla. Aprobado con un acto de aplausos del Regidor Señor Vasquez, por cuanto la creación de dicho plantel de educación no ha originado gastos algunos del Erario Municipal", asumiendo como preceptor Amador Machuca. ${ }^{3}$ En el mismo tenor, años más tarde se nombró a Marta Tapia como directora de la escuela municipal de San Pedro de Atacama, "en carácter de jefe de oficina y con los prorrogativos que como a tal le fija, tanto la ley de municipalidades en vigencia, como la ley de protección a los empleados municipales".39

El 10 de marzo de 1925 se realizó un diagnóstico sobre la situación escolar en el Departamento de El Loa. La información recuperada por los agentes fiscales arrojó lo siguiente:

“5).- En lo que se refiere a la Instrucción Pública en Calama hay solo tres escuelas funcionando, con las siguientes matrículas: Escuela $N^{\circ} 15$ con 250 alumnos, $N^{\circ} 9$ con 250, y Escuela Municipal con 100 alumnos. Las $N^{\circ}$ s 10 y 45 que existen en Chuquicamata fueron elevadas el año pasado a la categoría de escuelas superiores. Cada una de ellas tiene 700 alumnos. En cuanto a las que funcionan en Calama no han podido elevarse a superiores por no reunir los requisitos reglamentarios. En San Pedro de Atacamay el resto del departamento existen tres pequeñas escuelas con 139 alumnos de matrícula en total. Dicen los impugnadores del departamento que tan escasa población escolar no ha menester del nuevo organismo administrativo". ${ }^{4}$

Como el municipio de Calama administraba de forma autónoma las escuelas de toda la zona, generó una compleja

${ }^{36}$ ANFMC, vol. 2, n 4. Libro Actas de Sesiones de la Municipalidad de Calama. Fojas 229, 230, 243, 235, 237, 243, 247 y 250 ; 6 de junio de 1918.

${ }^{37}$ ANFMC, vol. 2, n ${ }^{\circ}$. Libro Actas de Sesiones de la Municipalidad de Calama. Fojas 310, 311; 24 de octubre de 1918.

${ }^{8}$ ANFMC, vol. 2, n 4 . Libro Actas de Sesiones de la Municipalidad de Calama. Fojas 422, 423 y 426; 23 de junio de 1919.

39 ANFMC, vol. 2. Decretos Administrativos 1924 a 1927. Calama, foja 333; 3 de marzo de 1925

${ }^{40}$ ANFIA, vol. 35. Oficio 193 (n 323). Calama, fojas 1-5; 10 de marzo de 1925. 
situación económica en sus arcas. En 1926, el alcalde manifestó que:

"[...] todas las escuelas municipales pasen hacer de cuenta del Fisco, pues en la actualidad es imposible armonizar los programas de enseñanza, que son distintos de los de las escuelas del Estado y que además es dificil poderse conseguir un personal de profesores para que sirvan en las escuelas municipales". ${ }^{41}$

Pese a la idea de que el Fisco asumiera en su totalidad los procesos de implementación y administración de los establecimientos educativos, hubo pobladores que estaban decididos a adjudicarse dichas responsabilidades comunitariamente, aunque con problemas de presupuesto. Es así como en Lasana una señorita estableció una escuela particular y se dirigió a la junta comunal de Educación solicitándole que consiguiera una subvención para su sostenimiento. Agregan que, con lo que pagan actualmente los alumnos, no alcanza a subvenir a sus necesidades, solicitando al alcalde una pequeña subvención. El alcalde respondió que los habitantes de Lasana poseen en la comunidad colindante de Chiu Chiu una escuela fiscal y que la distancia entre ambos poblados no es grande, por lo que es casi imposible que la "municipalidad les tenga la escuela al lado de sus viviendas". ${ }^{42}$ Ante tal panorama, los comuneros arguyeron en una nota a la Junta Comunal de Educación que era necesario:

“[... mantener la escuela fundada por la Sta. Amalia Núñez en el punto denominado Lasana, adjuntándose una nota firmada por diversos vecinos de la localidad donde se deja constancia que hay cincuenta niños en estado de recibir instrucción escolar".

Ante tal insistencia, la Junta Comunal de Educación asignó \$100 mensuales para subvencionar ese colegio como particular. ${ }^{43}$

En el documento citado se informa que en Peine, al Visitador de escuelas del municipio se le acercaron los vecinos señalando que en el poblado había "82 niños en estado de recibir instrucción escolar, que no sabían

\footnotetext{
${ }^{41}$ ACMC, Libro 9 (1925-1927), fojas 109, 110, 113, 114; 13 de abril de 1926.

42 ACMC, Libro 9 (1924-1927), fojas 211, 216, 217; 23 de octubre de 1926.

${ }^{43}$ ACMC, Libro 9 (1925-1927), fojas 237, 241; 2 de diciembre de 1926.
}

leer ni escribir por la falta de una escuela". De la misma forma, el alcalde manifestó que era imposible abrir una escuela en esa localidad por cuanto no se encontraría a una persona capacitada para que fuera a "desterrarse en esas serranías". Agrega que, "bastante se hará abriendo la escuela de Ollagüe y que ya se verán las dificultades en que se tropiezan para encontrar una profesora competente dispuesta a irse a Ollagüe por \$400 mensuales". ${ }^{44}$ Contradictoriamente, en 1927 se resolvió clausurar las escuelas de Ollagüe y Punta de Rieles, debido a que el primer alcalde exponía que:

"[...] se entiende en múltiples razones, para considerar la ineficacia de esas Escuelas que jamás son fiscalizadas ni cuenta con las comodidades que requieren y que Municipalidad no puede [ilegible] debido a su crítica situación financiera inflijan gastos al municipio, que le corresponden al Gobierno o a los industriales a Empresas particulares".45

Sin embargo, siguieron funcionando requiriéndose el "auxilio a la enseñanza pública gratuita y a los servicios de beneficencia, higiene, sanidad, y atención de desayuno escolar. En la actualidad la junta mantiene en breve condiciones cuatro escuelas, en Calama, Ollague, SPAy Peine". ${ }^{46}$ Información que es complementada el día 30 de septiembre del mismo año, donde se informa al ministerio que:

"Ministerio de educación pública: escuelas 1, 2, 3, 4, 5,6 y 7, funcionan normalmente, "al mismo tiempo dado la población escolar, y la distancia a ciertos mayores recursos para una mejor instrucción en lo que la infraestructura estima que los escolares I y 2 sean clasificados de "completos" dotar de los elementos necesarios para el objeto. Por carencia absoluta de instalaciones y personas, las escuelas números 5 y 6 pueden abarcar la población en total en esos puntos, por lo cual se hace necesarios dotar a estas escuelas de SPA [San Pedro de Atacama] y Toconao, de lo siguiente: Bancos o mesas para los niños, un ayudante para SPA y una ayudante para Toconao, como asimismo la construcción de una escuela en este último punto. Existiendo un hermoso terreno municipal frente a la plaza del pueblo y contando por otra parte con la ayuda de los vecinos para el objeto, todo lo cual puedo el

\footnotetext{
${ }^{44}$ ACMC, Libro 9 (1924-1927), fojas 211, 216, 217; 23 de octubre de 1926.

${ }^{45}$ ACMC, Libro 9 (1925-1927), fojas 109, 111; 13 de abril de 1927.

${ }^{46}$ ANFIA, circular 26. Municipalidad, El Loa. Calama, septiembre 20 de 1929.
} 
infraestructura comprobar en su última visita a esos lugares.

Ya esta creada una biblioteca por la junta de vecinos.

Se pone en forma el proyecto de un pequeño estadium

SPA 5000 hectáreas (agricultura)

Se pide ferrocarril Calama - SPA". ${ }^{47}$

La demanda de recursos a la municipalidad para seguir sosteniendo económicamente iniciativas como éstas, solo es posible comprenderlas porque existe una comunidad que desea colectivamente educarse. En síntesis, ilustrarse no es solo un proyecto emanado desde las cúpulas del Estado, sino que posee un correlato intenso en la población local, la cual se convierte en el motor de los proyectos etiquetados como modernizadores.

\section{* ¿El papel del estado o la escuela de papel EN EL Departamento de El LoA? (1930-1950)}

En el contexto histórico analizado, un punto de inflexión fue la Ley de Instrucción Primaria Obligatoria 3624 (1920), que dispuso la obligatoriedad de cuatro años como formación primaria, lo que fue determinante para la implementación de escuelas en los territorios fronterizos, donde la población local transitó entre la modernización emergente y los ámbitos tradicionales comunitarios de los atacameños. En 1929 desde la Intendencia de Antofagasta se difundió en toda la región que:

"Las únicas escusas que pueden eximir total, parcial o temporalmente del cumplimiento de la obligación escolar, en la forma de los artículos anteriores, son las siguientes: a) Que no haya escuela o no haya vacante en las escuelas situadas a menos de dos kilómetros o cuatro si se proporcionaren medios gratuitos de transporte". $4^{8}$

Sobre estos puntos, los agentes gubernamentales interpelaron a la población señalando que los adelantos y obras en materia educativa eran el "resultado del accionar fiscal"; complementado con que la labor educacional era:

"[...] intensa y de resultados halagadores; el espíritu de la reforma educacional toma caracteres tangibles, pues se ha demostra-

\footnotetext{
47 ANFIA, Ministerio del Interior, vol. 69 ( $n^{\circ} 310$ ). Calama, 30 de septiembre de 1929.

${ }^{48}$ Decreto con Fuerza de Ley 5291, 1929.
}

do un progreso notable en general. Donde continua la necesidad muy sentida de dotar de locales y mobiliario a la casi totalidad de los establecimientos de enseñanza de la provincia [...]. Durante el año funcionario con toda regularidad 74 escuelas fiscales; 12 superiores; 1 vocacional y 62 elementales, distribuidas por Departamentos en la siguiente forma: Antofagasta, 34; Tocopilla, 18; Taltal, 15 y El Loa 7".49

Estos establecimientos fueron atendidos por 74 directores y 158 profesores con nombramiento oficial del Estado y 82 nombrados y pagados por las Compañías Industriales. En el mismo tenor, desde la Intendencia de Antofagasta se argumentaba que:

"Merece consideración especial la enseñanza de los indios para lo cual es urgente refaccionary y ensanchar los doce locales fiscales de la ciudad de Calama y el de San Pedro de Atacama y dotar de edificios fiscales a las escuelas de Toconao, Chiu Chiu y Ollagüe o establecer internados gratuitos en San Pedro de Atacama y en Chiu Chiu". ${ }^{\circ}$

Pese a la singular muestra de los logros de la Intendencia, la realidad que hemos documentado era otra. $\mathrm{Mu}-$ chas de las escuelas implementadas en este período eran temporales, con profesores ambulantes que impartían la docencia "en ruinosos edificios", que en la mayoría de los casos eran propiedad de comuneros que los cedían para tal fin. ${ }^{51}$ Aunque el municipio se presentaba como una alternativa para la gestión educativa, esta agencia debió sortear problemas vinculados con el financiamiento generado por la falta de recursos provenientes desde Santiago. A saber:

“[... la I. Municipalidad de Calama ha acordado suprimir para el presente año la Escuela Municipal de Hombres que funciona en esta localidad, por razones de economías. Los alumnos que atendia esa escuela han debido concurrir a la escuela fiscal que se ha hecho estrecha para contenerlos. Como el Supremo Gobierno no pueden el presente año consultar fondos para nuevos arrendamientos de locales escolares no es posible pensar en dotar a la escuela de hombres de Calama de un anexo aunque las necesidades así lo exijan y ante esta situación el único temperamento

\footnotetext{
${ }^{49}$ ANFIA, vol. 90, Memoria Anual n 250; 14 de febrero de 1930.

${ }^{50}$ ANFIA, vol. 90. Memoria Anual n² 250; 14 de febrero de 1930.

51 ANFIA, vol. 206, Intendencia de Antofagasta, 13 de diciembre de 1930 (n०409).
} 
que es aconsejable es solicitar del Sr. Alcalde ceda al Fisco para un nexo de la escuela \#1 de Hombres de Calama el local de la Escuela Municipal". ${ }^{2}$

Aunque, el esfuerzo de algunos funcionarios era un aliciente para la comunidad, en esta época es difícil concebir a la escuela como una institución robusta. Si bien recibió cierto impulso desde el Estado, intentando a través de ella de disciplinar y "civilizar" a la población; en la práctica, el principal motor recae en la ciudadanía de Atacama. En 1926, en el pueblo de Peine los lugareños nuevamente realizaron gestiones para acceder a la educación primaria:

"[... en la localidad de Peine al interior de San Pedro de Atacama, en su visita última a esas regiones, se le acercaron los vecinos y le hicieron presente que hay 82 niños de ambos sexos en estado de recibir instrucción escolar que no sabían leer ni escribir por la falta de una escuela. El señor Alcalde manifiesta que es lamentable el estado de esos niños, pero que será imposible abrir una escuela en esa localidad por cuanto no se encontraría una persona capacitada para que con un sueldo de trescientos o cuatrocientos pesos, fuera a desterrarse en esas serranías". 53

En el poblado de Socaire en 1930, el panorama escolar era el siguiente:

"Me permito informarle con relación a algunos problemas del distrito de 'Socaire' de este departamento, los que no han sido comunicados por el [...] Joel Valenzuela Mosquera, Director de la escuela de esa localidad, comunicando el efecto por los vecinos... 3․) ESCUELA: este pueblo esta dotado de una escuela cuyo ruinoso edificio se compone de una sola sala, carente de [...] mueblesy útiles. Es indispensable dotarla de inmobiliarios, textos y utiles de enseñanza a fin de poder realizar mas efectiva labor educacional

\footnotetext{
52 Archivo Intendencia de Antofagasta (en adelante AIA). Vol. 99 Inspección Provincial de Educación Primaria 1931 (n 194-213). Además, se informa que: "Se han hecho numerosas gestiones en el sentido indicado anteriormente por el Director de la Escuela \#1 de Hombres, sin que hasta hoy se siga con una resolucion favorable pues se piensa ocupar el local, de referencia en un Laboratorio Quimico y Correo- Al suprimirse la escuela Municipal \#1 de Calama asi como la de San Pedro de Atacama en donde la I. Municipalidad solo costea un profesor y en el local ha hecho economias considerables en los servicios de educación, por lo cual estimo que no le ceria honeroso ceder ademas el local de la ex-escuela Municipal de Calama al Fisco para anexo de la Escuela \#1 de hombres. El sitado local fue costruido de acuerdo con las disposiciones de la Ley para la escuela."

${ }^{53}$ ACMC, Libro 9, foja 211; 23 de octubre de 1926.
}

en una region que aun no esta grande para nuestra nacionalidad.Junto decir que los habitantes no se estiman chilenos y mantienen en sus hogares libros de lectura y otros de origen boliviano". 54

Un cuadro muy desolador y contradictorio para la administración chilena y sus discursos, pues incluso hay una escasez de textos nacionales que interpela al rol de éste; como constatamos, aun en plena década de 1930 circulan libros de lectura de origen boliviano. El material bibliográfico para las escuelas de los poblados y oasis que circulaba por Atacama a fines del s. XIX era el siguiente: "Silabario 205 ejemplares; el libro de los niños 120 id. El [i?] de los niñitos $100 \mathrm{id}$. El maestro 220 id. Lecciones sobre el universo 80 id. Catecismo 285 id. Gramática castellana 265 id. Aritmética 245 id. Geografía 270 id. Sistema métrico 180 id. Muestras de caligrafía 15 id." 55 Los textos educativos utilizados para la instrucción primaria durante la década de 1930, de acuerdo a los antecedentes recopilados por Carrasco y Gavilán (2012) para el caso de los pueblos aymara, eran los mismos del área urbana y del resto del territorio chileno..$^{56} \mathrm{~A}$ esto debemos sumar la calidad de la dotación docente, que en algunos lugares presenta deficiencias, tal como describe el visitador Lino Montecinos el 19 de febrero de 1931, el cual en una de sus inspecciones a la escuela de Chuquicamata dirigida por Favio Muñoz Herrera informa que:

"[...] ha podido observar que este plantel de educación primaria no llena ampliamente su objetivo por la falta de preparación cientifica de su Director Muñoz Herrera, quien no responde a los nuevos metodos de enseñanza con la implantación de la reforma educacional, en sus diferentes aspectos". ${ }^{57}$

En marzo del mismo año, la municipalidad de Calama acordó suprimir "la Escuela Municipal de Hombres que funciona en esta localidad, por razones de economías", pese a que el establecimiento fue construido de acuerdo a las disposiciones legales. El municipio ante esta eventua-

\footnotetext{
54 ANFIA, vol. 206, 13 de diciembre de 1930 ( $\mathrm{n}^{\circ}$ 409).

55 AIA, vol. 2. Ministerio de Justicia (1879-1883). N 1627 . Santiago, 13 de octubre de 1880 .

${ }^{56}$ Los libros educativos chilenos eran: Silabario Matte (1902), El nuevo lector americano (1928), El lector chileno (1928); Silabario hispanoamericano (1945), Silabario para adultos 'Mi Tierra' (1946), Lea en colores (1946), entre otros.

57 ANFIA, vol. 99. $\mathrm{N}^{\circ}$ 104. Dirección Escuela n 3 de Chuquicamata (n 104). Foja 1. Calama, 19 de febrero de 1931.
} 
lidad sugiere ceder el local al fisco como un anexo de la escuela $\mathrm{N}^{\circ}$, para que los alumnos no quedaran sin escuela. ${ }^{58}$ Esta situación se repetía en los pueblos aledaños. En Socaire en 1932, el delegado municipal solicitó con urgencia puertas y ventanas para el edificio de la escuela, y además que se envíe un profesor y útiles de escritorio. ${ }^{59}$ Dicho escenario de gestión en el ámbito no va a cambiar, debido a la crisis económica de $1930 .{ }^{60}$

En tal sentido, podemos ilustrar otros casos llamativos: en una nota, el inspector educacional demanda que se regale a la escuela de niñas el techo del antiguo mercado municipal para construir un galpón que sirva de recinto educacional. El alcalde responde que:

“[...] la propiedad del terreno del Mercado está en litigio, y que no es posible conceder tampoco los materiales para mejora de un edificio Fiscal. Le ofreció al señor Villalobos hacer el galpón en el edificio Municipal para evitar dificultades, y estima que solo así debe procederse.- [además] el señor García dice que no es posible que la Municipalidad esté cumpliendo la deficiente labor del Fisco en materia educacional y que está en completo acuerdo con las ideas del señor Alcalde" (el subrayado es nuestro). ${ }^{61}$

A tal situación llega la ineficacia, que en sesión ordinaria del 8 de agosto de 1935 se sugiere la itinerancia de un profesor por las escuelas:

"No habiéndose obtenido hasta hoy, a pesar de las notas enviadas, que vengan a desempeñar sus cargos los profesores nombrados por el Fisco para que regenten las escuelas Fiscales de San Pedro de Atacama, Toconao y Peine, se acordó en sesión del día 25 de julio ultimo nombrar un profesor ambulante que visite dichas escuelas y preste en ellos sus servicios. A este respecto, el señor Alcalde manifiesta de que está buscando el profesor a quien encomendar los servicios que se dejan expresados". ${ }^{62}$

\footnotetext{
${ }^{58}$ ANFIA, vol. 99. Inspección provincial de educación primaria ( ${ }^{\circ}$ 194-213). Foja 1. Antofagasta, 13 de marzo de 1931.

${ }^{59}$ ACMC, Libro 12. Actas y Decretos. Foja 17; 28 de abril de 1932.

${ }^{60}$ Estos casos describen un panorama generalizado y evidencian problemas similares para la implementación de escuelas en todo el Norte Grande, y está registrado por González (2002), Castro (2004), Mondaca (2008) y Díaz y Ruz (2009), entre otros.

${ }^{61}$ ACMC, Libro 12 (1932-1936), continuación del Acta del 14 de abril de 1932 copiada a fojas [i?] del Libro 11; Foja 1.

${ }^{62}$ ACMC, Libro 12. Actas y Decretos; 8 de agosto de 1935.
}

Ante tal desalentador panorama, nuevamente los pobladores activarán mecanismos comunitarios para acceder a la ya histórica demanda por la educación. En Toconce se requirió que el municipio designara "un delegado... y se estudie la manera de crear allí una escuela mixta, pues una población escolar superior a 50 niños. Toconce cuenta con un edificio para el objeto, construido por los vecinos y designado 'casa Comunal'." ${ }^{33}$ Igualmente, en Caspana los comuneros decidieron construir un establecimiento, llamando la atención de las autoridades locales:

"El señor alcalde manifiesta que los habitantes de ese pueblo han dado principio a la construcción de un edificio para el funcionamiento de una escuela; que con el objeto de procurar alguna ayuda para dicho fin, consistente en pólvora, herramientas y víveres primeramente se dirigieron al gobierno y posteriormente a la municipalidad que conversó sobre este asunto con el señor Ballesteros, quien estuvo conforme en que se ayudara a esos habitantes, y que les ha proporcionado para tal objeto los elementos necesarios de trabajos que le solicitaron". ${ }^{64}$

Como hemos verificado, son los atacameños los que asumen un protagonismo al pronunciarse por demandas ciudadanas como la educación, siendo proactivos frente a los procesos de modernización que en la región se estaban experimentando en materias vinculadas a la extracción minera. La población regional, y particularmente los atacameños, se integraron a estos procesos económicos y sociopolíticos, constituyéndose los pueblos en cajas de resonancia de los cambios sociales a nivel regional. Dicho sea de paso, tanto vecinos como comerciantes y familias acaudaladas de Calama contribuyeron para impulsar la construcción de establecimientos educacionales, el pago a profesores, la donación de libros, incluso entregaron terrenos y casas para el funcionamiento de las escuelas y liceos, contando con el apoyo del municipio. ${ }^{65}$

\footnotetext{
${ }^{63}$ ACMC, Libro 12. Sesión Ordinaria, 26 de diciembre de 1936.

${ }^{64}$ ACMC, Libro 15, foja 428; 28 de marzo de 1944.

${ }^{65}$ En adelante nos remitiremos al área urbana, específicamente a Calama, donde se espera el aporte estatal para la implantación definitiva de la escuela fiscal en estos espacios, es decir de la Escuela Vocacional, situación que dista mucho de lo ocurrido realmente, aunque en las zonas interiores el aporte es netamente de los vecinos y comuneros atacameños. Sobre este tema existe diversa documentación histórica en el Archivo de la Corporación Municipal de Calama. Para un mejor detalle revisar los siguientes documentos: ACMC, Libro 12, fojas 228, 1934 / Libro 13, foja
} 
A partir de 1933, el Estado proyectó la instalación de la Escuela Vocacional y la Escuela Normal, en un intento por traspasar la escuelas municipales al Fisco. El 24 de enero de 1934, el Inspector Provincial de Educación notifica que "se le comunique que la Municipalidad acordó la suma de 26 mil pesos para la creación de la Escuela Vocacional". ${ }^{66}$ Para el 4 de abril se ratifica esta situación en Calama, manifestándose al alcalde "que desde el $1^{\circ}$ de enero último el Municipio nada tiene que hacer con las escuelas que eran hasta esa fecha municipales que pasaron a ser fiscales por la creación de las escuelas vocacionales hecha por el Ministerio respectivo". ${ }^{67}$ Empero, en la práctica, el Fisco estará ausente incluso con el proyecto de las escuelas vocacionales. ${ }^{68}$

Un año después, el Rotary Club se empeñará en cumplir esta labor, ${ }^{69}$ solicitando ayuda al municipio, el cual aceptó "siempre [que] el fisco cumpliera también con el compromiso de destinar la suma que le corresponde" ${ }^{\circ}$ Pese a los esfuerzos por tener un cuerpo educacional centralizado, quedó en evidencia el débil accionar del Esta-

30. 1936 / Libro 13, fojas 25-26. 1936./ Libro 13, foja 44. 1936./ Libro 13, foja 280. 1936./ Libro 13, foja 363. 1938 / Libro 13, foja 371, 1938./ Libro 13, foja 380. 1938./ Libro 14, foja 13. 1938 / Libro 14, foja 140. 1938./ Libro 14, foja 146. 1938./ Libro 14, foja 129. 1938./ Libro 13, foja 130. 1938./ Libro 14, foja 163. 1938./ Libro 14, foja 152. 1938./ Libro 14, foja 421. 1940./ Libro 14, foja 301. 1940./ Libro 14, foja 392.1941./ Libro 15, fojas 56-57, 1942./ Libro 15, foja 260. 1943./ Libro 15, foja 428. 1944./ Libro 17, foja 89. 1949./ Libro 17, foja 17. 1950./ Libro 17, foja 218. 1950 / Libro 17, foja 285. 1951./ Libro 17, foja 231. 1952.

${ }^{66}$ ACMC, Libro 12 (1932-1936), fojas 246, 247; 24 de enero de 1934.

${ }^{67}$ ACMC, Libro 12 (1932-1936), fojas 277, 279; 4 de abril de 1934.

${ }^{68}$ Incluso el municipio local asume el apoyo fiscal, como se observa en el siguiente documento: "Comunicación del Director de la Escuela de Hombres $N^{\circ} 6$ de San Pedro de Atacama.- Expresa el señor Alcalde que sobre esta cuestión ha recibido una comunicación del Rotary Club de Calama hecha a instancias del señor Director que como lo ha manifestado muchas veces, el Desayuno Escolar solo cuenta con la cuota municipal; y la cuota que corresponde al Fisco, no se ha recibido nunca, al menos mientras él ocupa el cargo de Alcalde.- De ahí que haya escasez de fondos. Termina diciendo que tratará esta cuestión tan pronto se reúna la Junta de Auxilio Escolar y tan pronto llegue el Secretario de ella, el Director escolar señor Villalobos.- Así quedó acordado." ACMC, Libro 12 (1932-1936), fojas 289, 292; 2 de mayo de 1934. Para mayores detalles revisar: Sesión Ordinaria celebrada el 11 julio de 1935; foja 417. Sesión Ordinaria celebrada el 8 de agosto de 1935 ; foja 436.

${ }^{69}$ ACMC, Libro 12 (1932-1936). Fojas 381, 382; 9 de enero de 1935.

${ }^{70}$ ACMC, Libro 12 (1932-1936). Foja 384; 23 de enero de 1935. do, incluso no lograba concretar la implementación de la Escuela Normal de Antofagasta, solicitando los recursos a los municipios nortinos:

"Escuela Normal para hombres en Antofagasta: El señor Alcalde dio cuenta de una comunicación recibida del señor Alcalde de Tocopilla, por la cual solicita la cooperación de las municipalidades de las provincias de Tarapacá y Antofagasta, a fin de obtener la creación en Antofagasta de una escuela normal para hombres.La junta acuerda prestar su concurso [...] a la idea propuesta a fin de obtener su realización, y al efecto se autoriza al señor Alcalde para que se dirija al supremo gobierno, haciéndole presente la conveniencia de realizar la obra propiciada por la $H$. Junta de Vecinos de Tocopilla." ${ }^{11}$

En 1937 aun no se concretaba la implementación de la Escuela Vocacional, y aunque el municipio de Calama facilitó maquinarías y construyó un horno, gestionando a su vez un local y "se adquirirían los muebles y elementos necesarios para él presente año", además de ayudar a los "escolares faltos de recursos" y becar a algunos estudiantes, aun "se tramita la ampliación de sus actuales locales, sin haberse llegado a nada positivo". Se plantea que en 1938 se estudie la forma "de dar posibilidades a los escolares que terminan sus estudios primeros y quieran continuar con el aprendizaje de alguna profesión siendo esto una obra exclusivamente del municipio". ${ }^{2}$

Esta labor se ve acompañada de otras instancias educativas como la:

“[...] cooperación espontánea y desinteresadamente del señor director de la Escuela de Hombres de esta ciudad, don Guillermo

\footnotetext{
${ }^{71}$ ACMC, Libro 12 (1932-1936). Sesión ordinaria celebrada el 6 de febrero de 1935; Fojas 391, 393. También se agrega que en el: "Centro Protección Social del niño: Se dio lectura a una presentación de esta Institución solicitando la ayuda de la Municipalidad para una gira de estudio y recreo con 20 niños de San Pedro de Atacama, Toconao y Calama a Antofagasta [...] Chuquicamata.- Se acordó contribuir con $\$ 100 "$. También, existieron escuelas granjas, a las que se refiere el alcalde que manifiesta en una convención en Iquique que: “[...] en conformidad a la autorización concebida por la municipalidad de Calama, presento en la segunda convención de alcaldes del norte, celebrada en Iquique, los trabajos sobre "Creación de escuelas granjas en Calama y San Pedro de Atacama". ACMC, Libro 13 (1936-1939). Sesión ordinaria celebrada el 28 de mayo de 1936. Foja 1. Una de ellas estuvo ubicada en Quillagua.

${ }^{72}$ ACMC, Libro 13 (1936-1939). Sesión extraordinaria celebrada el 13 abril 1937. Foja 179.
} 
Carvajal y personal de profesores. Se tomara la Matricula de solo alumnos, considerándose el funcionamiento de un solo curso y especialmente para adultos, curso que se le daría el carácter de industrial. Las materias a tratarse serian: Aritmética, Castellano, Contabilidad, Geometría, Elemento de Mecánica y Dibujo Lineal, $y$ conocimientos generales talvez de idiomas. A cargo de estos cursos estará el personal municipal que ha ofrecido todo su concurso a esta obra".

Es decir, la misma escuela tendrá múltiples funciones, en este caso una escuela nocturna. ${ }^{73}$

Sobre la participación del municipio en la misma sesión del 23 de octubre de 1937, en las Actas se refiere como a un establecimiento "Vocacional Municipal", que también está:

"[...] considerada en el presupuesto de 1938, dice sobre ello, que conversara con el Inspector Departamental de Educación, para arreglar todo cuento se relaciona con su funcionamiento, con el bien entendido que el Fisco nada tendrá que inmiscuirse en este Establecimiento y lo que trate el señor Inspector, deberá ceñirse a lo que estime conveniente la Municipalidad" (el subrayado es nuestro). ${ }^{74}$

73 ACMC, Libro 13 (1936-1939). Sesión Ordinaria celebrada el 23 de Octubre de 1937. Foja 288. En Sesión ordinaria celebrada el 8 de mayo de 1937. Fojas 205, se informa de la Solicitud de la Directora de la Escuela de Niñas, quien: "[...] solicita que la Ilustre Municipalidad mantenga los \$2500 que se consultaron para el Grado Vocacional de Calama por el presente año, para destinarlo al curso de modas y economía domestica de esta ciudad en virtud de haber sido trasladado el Grado Vocacional de Calama a la Ciudad de Antofagasta. El Regidor Sr. López estima improcedente que se desglose de esta Partida que se destino para el mantenimiento de los Grados Vocacionales, esta cantidad de dinero para destinarla al curso de Economía Doméstica".

${ }^{74}$ ACMC, Libro 13 (1936-1939). Foja 292. También se informa que: "Como para la instalación de esta escuela se, se necesitara, un local adecuado, el señor Alcalde notificara a la autoridad que la Corporación ocupara desde el próximo año, el local e propiedad del Ministerio que queda ubicado en la calle Vicuña Mackenna, al lado de los baños Municipales, en donde funciona el anexo a la Escuela de Hombres y que actualmente esta facilitando al Fisco. Habrá esta notificación en razón de que se ha podido imponer que este local es demasiado para el anexo que funciona en el; pues, en el ultimo caso, con que solo ocupen los niños una sola, es suficiente, ya que, el numero de estos alumnos es muy reducido.- Haciendole algunas reparaciones, este edificio quedara en perfectas condiciones para ser usado por la escuela vocacional Municipal". El subrayado es nuestro.
La Escuela Vocacional definitivamente se inaugura el 2 de mayo de 1938, dependiendo de la participación directa de la municipalidad de Calama, durante este proceso inmediatamente:

"[...] se nombró al Regidor señor Manuel Chávez para que en representación del Municipio integre el Consejo de ese establecimiento y al Doctor don Carlos Glasinovic en representación de los vecinos, dejándose, para ser nombradas por la Junta Permanente de Adelantos Comunal, las tres demas que integrarán este Consejo" 75

Meses más tarde se acordó "la instalación y funcionamiento en el próximo año de ese curso de economía doméstica" ${ }^{76} \mathrm{La}$ instalación de este establecimiento permite que funcione como centro neurálgico de las diversas actividades educativas, tales como la escuela nocturna, el préstamo de un local a la escuela de hombres y un taller. Al mismo tiempo, reproduce el carácter cívico, se realizan las celebraciones nacionales, en este sentido el año 1939 se comienza a usar el patio para las "alocuciones patrioticas y las veladas nacionales".77 El municipio local seguirá actuando como el eje estructural de la educación en toda la zona. Un ejemplo concreto de esto ocurre en marzo de 1942, fecha en la cual la Unión de Profesores de Chile solicita que "la Municipalidad le facilite el local de la Escuela Vocacional, a fin de que allí funcione el Liceo Nocturno, diariamente desde las 19 hasta las 21.30 horas". ${ }^{8}$ Se impulsó desde esta institución la idea de construir una bodega con el fin de guardar las máquinas de coser, estantes y pizarrones, además de cerrar el patio, construir servicios higiénicos para los alumnos del Liceo

75 ACMC, Libro 13 (1936-1939). Sesión extraordinaria celebrada el 17 de marzo de 1938. Foja 363.

${ }^{76}$ ACMC, Libro 13 (1936-1939). Sesión ordinaria celebrada el 9 de diciembre de 1938 por la I. Municipalidad de Calama. Foja 28.

77 ACMC, Libro 14 (1939-1941). Sesión extraordinaria celebrada por la I Municipalidad el 17 de mayo de 1939. Fojas 151-152.

${ }^{78}$ ACMC, Libro 15 (1941-1944). Sesión Extraordinaria celebrada por la I. Municipalidad el 29 de marzo de 1942.- Foja 260. Se agrega: "El señor Parra, manifiesta que no se han principiado los trabajos de encielado y piso de la Sala de economía Doméstica de la Escuela Vocacional; por cuanto no había llegado la madera que se encargo; que con respecto a la solicitud que hace la Unión de Profesores, visito el local de ese Plantel Educacional a fin de establecer si este reunía las condiciones necesarias para que tanto el Liceo Nocturno como la Escuela Vocacional funcionaran en las mayores comodidades disponibles; que dicha visita la efectúo en compañía de la señora Directora de esa Escuela [...]." 
Nocturno, etc. La Dirección de Obras y Servicios Municipales informa el 29 de marzo de 1943 que todas estas ideas se llevarán a cabo a la brevedad. ${ }^{79}$

Pese a la descoordinación entre el gobierno central y sus representantes locales, el municipio intentó implementar políticas educativas en favor de su población. El 11 de junio de 1943 llegaron a Calama cuatro profesoras para trabajar en la Escuela Taller Fiscal No 88 que supuestamente funcionaba en esta ciudad; estas maestras fueron a la Gobernación para requerir datos sobre el lugar donde estaría ubicado el edificio de dicho plantel. Como en esa repartición pública:

“[...] no tenían ningún conocimiento al respecto, consultó este asunto al Director Gnal. De Educación Primaria, quien le contesto no saber nada y dio instrucciones de que esos profesores permanecieran en Calama; que estimando que no perjudicaría al funcionamiento de la Escuela Vocacional Municipal de Calama, que dicha Escuela Taller Fiscal funcionará en el edificio de ese plantel, y que por el contrario ello beneficiaria a la población. Le ofreció al Director de Educación Primaria el local de esa Escuela, como asimismo poner a disposición las cuatro maquinas de coser y la de tejer y además darle una asignación anual de cinco mil pesos para el funcionamiento de esa Escuela Taller; que son cuatro las profesoras enviados por el Gobierno". ${ }^{\circ}$

Se agrega al respecto que:

"La escuela taller funcionará en la escuela vocacional municipal, puesto será un aporte para este establecimiento y para que no se lleven esta iniciativa a otro lugar de la republica, se propone que se envía un telegrama a S.E. el Presidente de la República, con copia para el Ministro de Educación Pública ofreciéndole dicha cooperación.- Por unanimidad se acordó ofrecerle al Supremo Gobierno la cooperación de la Municipalidad relativo a proporcionarle su calidad de préstamo al edificio de la Escuela Vocacional Municipal de Calama, cuatro máquinas de coser, una de tejer y la suma de cinco mil pesos anuales para el funcionamiento de la Escuela Taller Fiscal $N^{\circ} 88^{\prime \prime} .^{81}$

\footnotetext{
${ }^{79}$ ACMC, Libro 15 (1941-1944). Sesión Extraordinaria celebrada por la I. Municipalidad el 29 de marzo de 1942. Fojas 260, 261.

${ }^{80}$ ACMC, Libro 15 (1941-1944). Sesión ordinaria celebrada por la I. Municipalidad el 11 de junio de 1943. Fojas 311, 312 y 113.

${ }^{81}$ ACMC, Libro 15 (1941-1944). Sesión ordinaria celebrada por la I. Municipalidad el 11 de junio de 1943. Foja 329.
}

En noviembre de 1943:

"Se dio lectura al Decreto 7014, del Ministerio de Educación Pública, por el cual se acepta desde el $1^{0}$ de julio último, y por el plazo de tres años, la cesión gratuita que a favor del Fisco hace la I. Municipalidad de Calama del local de su propiedad ubicado en esta ciudad, calle Vicuña Mackenna s/n a fin de destinarlo al funcionamiento de la Escuela Vocacional $N^{\circ} 88$ del Departamento de El Loa". ${ }^{2}$

En 1949 se informa de la "habilitación y terminación del pabellón de la escuela vocacional de esta ciudad.- Calama, 12 de mayo de 1949"; conjuntamente, se establece la necesidad de que para un cómodo funcionamiento de las labores de la Escuela Vocacional de Calama, es necesario ejecutar algunos trabajos en el recinto, demostrando la precariedad de los edificios escolares hacia mediados del s. XX. ${ }^{83}$ Teóricamente, el Estado chileno fue personificado regionalmente por el municipio, aunque los dispositivos sociopolíticos en materia educacional responden a una praxis local, con una impronta periférica, robustecida por el accionar de agentes locales. Por ejemplo, en mayo de 1952, la directora de la Escuela Vocacional plantea las diversas necesidades de su establecimiento, y solicita "a la Corporación que interceda ante quien corresponda para solucionar el grave problema al lado al Internado de esta Escuela que, de no ser resueltas sus dificultades dentro de un corto tiempo, tendrá irremediablemente que cerrar

\footnotetext{
$\overline{82}$ ACMC, Libro 15 (1941-1944). Sesión ordinaria celebrada por la I. Municipalidad de Calama el 26 de noviembre de 1943. Foja 403.

${ }^{83}$ Servicios higiénicos del pabellón.- reboque de 72,00 metros cuadraos de muros afinado de 72,00 metros cuadrados de muros.- Pintura de 90,00 metros cuadrados de muros y cielos, esta postura debe ser al óleo, para el efecto de la construcción del envigado, encalaminado, con la colocación de 4 tigerales 2 vigas transversales y el cielo de 18, oo metros cuadrados. Colocación de los centros y forros para la habilitación de una puerta.- pabellón de la escuela vocacional.- Confección y colocación de 11 tijerales.Confección y colocación de 11 vigas transversales.- Colocación de costaneras para cubrir 203 metros cuadrados de encalaminado- Encieladura de 170,00 metros cuadrados colocación de durmientes para cubrir 27,00 metros cuadrados de piso.- Colocación de un tabique de 62,00 metros cuadrados.- Colocación de 8 ventanas tipo semi-modernas.- Colocación de una puerta de dos manos (hojas) pinturas de 280,00 metros cuadrados de muros.- Colocación de 42,00 metros de cornizón de 0,30 metros de alto.Es cuanto puedo informar al señor alcalde Fdo. Ramón Galecio ArévaloAyte. de la D. de O. y Sal. Hay un timbre".
} 
sus puertas" ${ }^{84}$ En otras palabras, la principal escuela del área, puede cerrar dada la crisis del sistema. El alcalde expuso que la escuela ha funcionado gracias a la ayuda de la municipalidad, y que él ha podido comprobar la autenticidad de lo expuesto por la Directora, y que por tal motivo exigía la aprobación de los regidores, para dirigirse a los organismos correspondientes, solicitando a nombre de la Corporación, la solución al Fisco para estos problemas. ${ }^{85}$

En la medianía del s. XX, no solo en el área urbana de Calama el Estado chileno presentaba vacíos en la aplicación e implementación de proyectos educativos, sino que también hacia las áreas rurales se extendía esta situación que se venía repitiendo desde inicios del siglo. Como corolario de lo que hemos discutido desde la evidencia archivística, una de las escuelas que tardíamente logra definitivamente implementarse, fue la de Lasana. Aquí, los comuneros manifiestan haberse reunido el 19 de julio de 1953 para organizar un Centro de Padres que tenía como objetivo "solucionar varios problemas que afectan a la educacion primaria". ${ }^{86}$ Como queda establecido en el citado documento de la comunidad, una de las primeras acciones fue requerir al municipio de Calama los materiales de cons-

\footnotetext{
${ }^{84}$ ACMC, Libro 17 (1948-1952). Acta de la Sesión Extraordinaria celebrada por la Ilustre Municipalidad de Calama con fecha viernes 30 de mayo de 1952. Fojas 443-444.

${ }^{85}$ ACMC, Libro 17 (1948-1952). Acta de la Sesión Extraordinaria celebrada por la Ilustre Municipalidad de Calama con fecha viernes 30 de mayo de 1952. Fojas 443-444.

${ }^{86}$ Los documentos de la comunidad señalan: "En dicha reunión por unanimidad de los asambleistas se acordo enviar una solisitud a la ilustre Municipalidad de la comuna de Calama. $1^{\circ}$ Primer punto. La contrucion de un edificio que sirva de escuela primaria. $2^{\circ}$ Segundo punto el profesor que se aga cargo de la escuela que sea fiscal o en caso contrario municipal. $3^{\circ}$ Terser punto la contrucion del edificio será contruida por los padres o apoderados de los niños cienpre que la municipalidad copere con semento calamina maderas y Materiales segundarios de contrusion. $4^{\circ}$ Cuarto punto los padres del centro se comprometen a ejecutar la cuntrucion completa o es decir la obra de mano [foja 4]. $5^{\circ}$ Punto dicha escuela estara Entalada en el centro de lazana de los solisitantes el sitio para la obra será estudiado por una comicion que la munisipalidad enviara el señor alcalde. Por lo tanto el señor Remigio Pastrana copera con tres mil adoves por el momento Señor Alcalde y señores rejidores esperamos que nuestra solicitud tenga buena acojida y de ante mano agradeciendo sus buenas atenciones Señor Alcalde aun damos un senso de los niños, sin aver otro punto que tratar se levanta la secion a las 4 de la tarde P.M.". Archivo Escuela de Lasana (en adelante AEL). Libro de Actas del Centro General de Padres y Apoderados Escuela de Lasana (1953-1966). Se agradece el aporte de esta documentación a Cristián Pérez (Pérez y Torrejón 2012).
}

trucción, comprometiendo los vecinos la mano de obra para los trabajos de edificación del recito educativo. Esta petición se dilatará por la no entrega de los recursos. En las Actas fechadas en 17 de enero de 1954, ante el atraso en la entrega de materiales, se anunció en Calama que de todas formas los trabajos se iniciarían el 8 de marzo, sino es "con cemento será con adobes", acordándose "edificar la Escuela por la Comunidad". ${ }^{7}$

En libro de Actas de la Comunidad de Lasana, quedan explícitos algunos puntos relevantes de lo que hemos problematizado:

" $I^{0}$ Punto se acordó nombrar el sitio pa la escuela se propuso al señor Nicanor Galleguillos que si podia vender una parte de terreno, el señor Nicanor Galleguillos da la respuesta inmediato que el no podria vender. Pero el si lo dona el terreno pa la escuela ya que es un bien para nuestro pueblo y un adelanto pa los niños el direstorio y la asamblea se pronuncia de acuerdo". ${ }^{88}$

En el mismo manuscrito aparece el aporte de los trabajadores de la empresa minera de Chuquicamata, recursos que fueron solicitados por los lugareños, recibiendo "un dinero que se recolestó en Chuquicamata que suma un total de tres mil cien pesos \$ 3100 y asi entrega al señor tesorero personalmente"; incluso parte de los obreros "fueron de gran ayuda en el momento de levantar los muros de piedra" de la escuela. El 2 de junio de 1957 culmina un largo proceso de ausencias del sistema educativo chileno, donde los protagonistas ciertamente fueron la agencia municipal, los privados y los comuneros atacameños. ${ }^{89}$

\section{* Comentarios finales}

Desde la organización de la Intendencia de Antofagasta, en 1888, el Estado chileno se interesó, como era de suponer, más en los puertos y enclaves mineros de la pampa que en los poblados rurales del interior de la nueva provincia, debido a que su fin último, siguiendo la lógica del Estado moderno, era "garantizar un orden social que permita el funcionamiento y reproducción de un sistema productivo y de una estructura de clases sociales" (De la

\footnotetext{
${ }^{87}$ AEL, foja 8; 17 de enero de 1954 .

${ }^{88}$ AEL, foja 9; 14 de febrero de 1954.

${ }^{89}$ AEL, foja 26.
} 
Peña 1986: 27). Por el contrario, pensamos que se produjo cierto ausentismo y desinterés de las autoridades metropolitanas, manifestado a nivel local en el accionar de los subdelegados (Mondaca et al. 2011). En la práctica, la escasa gestión estatal habría permitido que la población en los oasis, quebradas y cordillera andina ejerciera el poder local con un alto grado de autonomía, principalmente entre los vecinos de mayor prestigio (Sanhueza y Gundermann 2007). El impulso de los pobladores estuvo dirigido hacia una mayor identificación con el poder local, permitiendo un abanico de posibilidades en ventajas económicas, políticas y sociales con una fuerte tendencia a la autosuficiencia (Padua y Vaneph 1986).

En el contexto histórico analizado, el municipio paulatinamente se constituyó en una agencia que buscó mediar los espacios de poder, como una entidad intermediaria que fue organizando la administración gubernamental, concibiendo relaciones de diferente orden entre la comunidad, a nivel micro, y con Estado central a nivel macro..$^{90}$

\footnotetext{
${ }^{90}$ Desde un punto de vista económico y social, esta realidad sociopolítica se manifestó en grupos que disponen de iniciativas que no siempre son del interés de toda la población, sino que más bien responden a intereses individuales o de grupos más pequeños, pero que impactan a toda la población, ya sea porque algunos de ellos concentran los medios de producción, la tenencia de las tierras, o el poder político. En todo caso, siempre pueden manifestarse como un nexo entre grupos interrelacionados entre sí y con las instituciones, pues la búsqueda de una vida civilizada y
}

La demanda política de los actores locales tras movilizarse y generar recursos económicos y materiales al establecer vínculos con las agencias estatales, permitió articular las condiciones necesarias para la implementación de establecimientos educacionales que respondían a los anhelos ciudadanos de la población de los oasis y quebradas andinas; amén de los procesos de desarrollo productivo y minero del territorio de Atacama.

Este largo peregrinar por la historia de la institución escolar en el Departamento de El Loa, permite reflexionar acerca de cómo la población local articuló en concomitancia con el municipio de Calama, las condiciones necesarias para acceder a un derecho ciudadano de larga data en la región, como es la educación. Esta relación tiene como soporte las ideas de modernidad circulantes desde mediados del s. XIX en la frontera de Atacama; siendo una constante socio-histórica para comprender los procesos locales de construcción de la nación en los territorios del desierto de Atacama.

Agradecimientos Este artículo es resultado del Proyecto de Investigación Mayor de Ciencia y Tecnología de la Universidad de Tarapacá, Código 5712-13. Asimismo, se agradece el apoyo del Convenio de Desempeño Universidad de Tarapacá-MINEDUC.

moderna, es la base del cambio social de los agentes locales y la sociedad de El Loa en su conjunto (Mondaca et al. 2011).

\section{* Referencias citadas}

AGUIRRE, C. y C. MONDACA, 2011. Estado nacional y comunidad andina. Disciplinamiento y articulación social en Arica, 1880-1929. Historia 44 (1): 5-50. ARCHIVO NACIONAL. FONDO INTENDENCIA DE ANTOFA-
GASTASTA (ANFIA).

ARCHIVO NACIONAL. FONDO MUNICIPALIDAD DE CALAMA (ANFMC).

ARCHIVO CORPORACIÓN MUNICIPAL DE CALAMA (ACMC).

ARCHIVO ESCUELA DE LASANA. ACTAS CENTRO GENERALDE PADRES YAPODERADOS (LACPEL).
CASTRO, L., 2004. Una escuela fiscal ausente, una chilenización inexistente: La precaria escolaridad de los aymaras de Tarapacá durante el ciclo de expansión del salitre (1880-1920). Cuadernos Interculturales 2 (3): 57-68.

CAJÍAS, F., 1975. La provincia de Atacama (1825-1842). Instituto Boliviano de Cultura, Editora Universo, La Paz.

CARRASCO, A. y V. GAVILÁN, 2012. Influencia del proceso de enseñanza escolar fiscal en la socialización de mujeres y hombres aymara de la zona altiplánica del norte de Chile. Estudios Atacameños, Arqueología y Antropología Surandinas 44: 73-88.

CATULLO, M., 2006. Ciudades relocalizadas: Una mirada desde la antropología social. Editorial Biblos, Buenos Aires. 
MINISTERIO DEL INTERIOR DE CHILE. Decreto de Ley 1733 , 1885 .

MINISTERIO DEL INTERIOR DE CHILE. Decreto de Ley 3346, 1888.

MINISTERIO DEL INTERIOR DE CHILE. Decreto con Fuerza de Ley $5291,1929$.

DE LA PEÑA, G., 1986. Poder local, poder regional: Perspectivas socio-antropológicas. En Poder local, poder regional, J. Padua y A. Vanneph (Eds.), pp. 27-56. El Colegio de México, CEMCA, México D.F.

DÍAZ, A. y R. RUZ, 2009. Estado, escuela chilena y población andina en la ex subdelegación de Putre. Acciones y reacciones durante el período post Guerra del Pacífico (1883-1929). Polis 8 (24): 311-340.

FERNÁNDEZ, E., 2003. Estado y sociedad en Chile, 1891-1931. El Estado excluyente, la lógica estatal oligárquica y la formación de la sociedad. LOM Ediciones, Santiago.

GÓMEZ, D., 1995. Cultura y educación atacameñas. Instituto de Investigaciones Antropológicas de la Universidad de Antofagasta, Antofagasta.

GÓNGORA, M., 2006 [1986]. Ensayo histórico sobre la noción de Estado en Chile en los siglos XIX y XX. Editorial Universitaria, Santiago.

GONZÁLEZ, J. A, 2008. La conquista de una frontera: Mentalidades y tecnologías en las vías de comunicación en el Desierto de Atacama. Revista Geográfica Norte Grande 40: 23-46.

GONZÁLEZ, S., 2002. Chilenizando a Tunupa. La escuela pública en el Tarapacá Andino 1880-1990. DIBAM, Universidad Arturo Prat, Instituto de Estudios Andinos Isluga, Centro de Investigaciones Diego Barros Arana, Santiago.

INSTITUTO NACIONAL DE ESTADÍSTICAS (INE), 1889 , $1900,1910,1929$.

HIDALGO, J., 1984. Complementariedad ecológica y tributo en Atacama. 1683-1792. Estudios Atacameños 7: 422-442.

MARSHALL, T. y T. BOTTOMORE 1992 [1950]. Ciudadanía y clase social. Alianza Editorial, Madrid.

MONDACA, C., 2008. Identidades sociales y representaciones políticas en conflicto: El sistema educativo chileno en los Andes de Arica, 1884-1929. Anthropologica 26 (26): 33-62.
MONDACA, C. y J. P. OGALDE, 2012. Historia y memoria de la comunidad atacameña de la Banda. Calama, norte de Chile. Siglos XIX$X X$. Consejo de las Artes y la Cultura, Editorial M\&F Ltda., Iquique.

MONDACA, C., W. SEGOVIA y C. PÉREZ, 2008. Historia oral del norte de Chile: Memoria de los pueblos atacameños de Talabre, Camar Ayquina y Cupo. Ediciones Orizonta Producciones Digitales, Valparaíso.

MONDACA, C., W. SEGOVIA y E. SÁNCHEZ, 2011. Historia y sociedad del Departamento del Loa. Calama, una mirada desde los archivos. El municipio y la construcción social del espacio 1879-1950. Ediciones Orizonta Producciones Digitales. Valparaíso.

OCHMAN, M., 2006. La reconfiguración de la ciudadanía. Los restos del globalismo y de la posmodernidad. Instituto Tecnológico y de Estudios Superiores de Monterrey, México D.F.

PADUA, J. y A. VANEPH, 1986. Poder local, poder regional. El Colegio de México, CEMCA, México D.F.

PAREKH, B., 2000. El etnocentrismo del discurso nacionalista. En La invención de la Nación. Lecturas de la identidad de Herder a Homi Bhabha, A. Fernández (Ed.), pp. 91-122. Editorial Manantial, Buenos Aires.

PÉREZ, C. y K. TORREJÓN, 2012. Memorias lasaneñas. Fundación Escuela $N^{\circ} 18$. Servicio Gráficos Publicitarios, Arica.

SÁNCHEZ, E., 2010. Estado, sociedad y gobierno local en el Departamento de El Loa, norte de Chile: El rol de la Corporación Municipal de Calama (1879-1930). Tesis para optar al Grado de Licenciado en Educación y Título de Profesor de Historia y Ciencias Sociales. Universidad del Mar, Iquique.

SANHUEZA, C. y H. GUNDERMANN, 2007. Estado, expansión capitalista y sujetos sociales en Atacama (1879-1928). Estudios Atacameños, Arqueología y Antropología Surandinas 34: 113-136.

2009. Capitales, Estado rentista y cambio social atacameño en las regiones interiores de Antofagasta (1879-1928). Universum 24 (1): 218-246.

WOLF, E., 2001 [1956]. Figurar el poder. Ideologias de dominación y crisis. Centro de Investigaciones y Estudios Superiores en Antropología Social (CIESAS), México D.F. 